\title{
Формы подачи информации в новостном вещании: практики российских телеканалов
}

\author{
Элина Никольская \\ Михаил Макеенко
}

Ключевые работы отечественных ученых разных периодов, посвященные телевизионным жанрам, характеризуются доминированием теоретического осмысления с упором на филологическую базу над обобщением эмпирики, полученной на основе изучения актуальных рабочих практик редакций. В этой ситуации представленное исследование ставило своей целью выявление возможностей формирования иных подходов к выделению и определению типов представления телевизионного новостного контента аудитории.

Ключевые слова: теория журналистики, теории медиа, жанры журналистики, формы подачи информации, телевизионная журналистика.
(C) Никольская Элина Сергеевна кандидат филологических наук, старший преподаватель кафедры периодической печати факультета журналистики МГУ имени М.В. Ломоносова (г. Москва, Россия), elina_nik@mail.ru

(C) Макеенко Михаил Игоревич кандидат филологических наук, доцент кафедры теории и экономики СМИ факультета журналистики МГУ имени М.В. Ломоносова (г. Москва, Россия), makeenko.mikhail@smi.msu.ru

\section{Введение}

Среди важных особенностей отечественного академического дискурса журналистики и медиа, выделяемых специалистами (Вартанова (ред.), 2019), нам представляются особенно важными несколько характеристик. Одной из них можно считать формирование в исследовательском сообществе чисто научного, имеющего минимальный практический выход интереса к определенным областям знания, в большинстве стран развивающихся в рамках дискурса индустриального. Показательным примером этой тенденции можно считать обширный массив научной литературы по типологии СМИ, которая за рубежом чаще является предметом интереса издателей и маркетологов (Виноградова, 2019). Другая принципиально важная для нас характеристика исследовательских подходов доминировавшая на протяжении многих десятилетий и сохраняющаяся и сегодня нормативность и филологичность при изучении журналистики.

Указанные особенности стали, на наш взгляд, ключевыми факторами того, что одним из наиболее крупных направлений в исследованиях теории журналистики и медиа в СССР, а потом и в России стала классификация жанров, обширная жанровая теория. Международный, в первую очередь англоязычный академиче- 
ский дискурс, по сути, не включает в себя тематику и проблематику журналистских жанров (Чобанян, 2018), и варианты называния и определения различных форм подачи материала остаются внутренним делом конкретных редакций и медиаорганизаций (Crump, 1974; Hornby, 1965). В то же время в отечественной университетской науке можно говорить практически об отдельной научной школе исследований журналистских и, шире, медийных жанров (Ученова, 1982; Пельт, 1984; Кройчик, 2000; Тертычный, 2011; Лазутина, Распопова, 2012; Ким, 2004), имеющей лингвистические и литературоведческие корни. В целом к этой же научной школе можно отнести и ключевые работы, посвященные жанровой структуре телевизионного эфира (Борецкий, 1961; Багиров, Борецкий, 1967; Кузнецов, Цвик, Юровский, 2002): представленная в них классификация форм презентации информации в аудиовизуальном сегменте вышла из представлений о жанрах печатной журналистики и художественного творчества.

Так, в первом теоретическом исследовании информационных жанров активно развивавшегося советского телевидения Р.А. Борецкий (1961) выделял выступление, беседу и интервью. В отдельную группу («киножанры») попали киноинформация, кинорепортаж, документальный телефильм, особняком стоял телевизионный репортаж - показ события с комментариями. Спустя шесть лет в методическом пособии для практиков «Жанры телевидения» авторы попытались охватить все формы представления информации на телевидении (Багиров, Борецкий, 1967). Предложенная ими классификация была весьма хаотична, так как природа многих жанров, выделенных авторами, определялась по аналогии с другими средствами массовой информации, а среди классифицированных были такие жанры, как фотоинформация, кинозаметка, киноотчет.
Наибольшим авторитетом в преподавательской и исследовательской среде стала пользоваться типология жанров, предложенная В.Л. Цвиком (Кузнецов, Цвик, Юровский, 2002). Формы представления информации он классифицировал по трем группам: жанры информационной публицистики, жанры аналитической публицистики и жанры художественной публицистики, выделив в отдельную категорию документальный телефильм. Практически все теоретические разработки в области телевизионных жанров последних двух десятилетий были попытками развить представления В.Л. Цвика с опорой на традиционный методологический аппарат, в частности на наработки Л.Е. Кройчика (2000).

Например, Л.П. Шестеркина и Т.Д. Николаева (2012) разработали свою типологическую таблицу жанров тележурналистики, взяв за основу подход Л.Е. Кройчика, который вместо традиционного деления на информационные, аналитические и художественные жанры предлагал разграничить жанры по цели, которая лежит в основе решения творческой задачи автора. В итоге Л.П. Шестеркина и Т.Д. Николаева выделяли оперативно-новостные жанры, оперативно-исследовательские, исследовательско-новостные, исследовательские и исследовательско-образные. При этом авторы отказались от таких жанров, как выступление, корреспонденция и зарисовка, предложенных В.Л. Цвиком.

Немного позднее А.А. Хлызова (2015), также используя методологию Л.Е. Кройчика, представила еще одну систему телевизионных жанров, ставшую результатом формирования гибридных жанров и появления современных стратегий потребления информации. При этом она отмечала, что «для современного телевидения характерна не столько диффузия жанров, столько диффузия форматов и жанровых элементов» (Хлызова, 2015: 74). В исследовании информационных жанров, пред- 
ставленных на региональныхтелеканалах, О.Ф. Майдурова (2011) обращала внимание на невостребованные сейчас жанры из классической типологии: например, отчет и устное информационное сообщение. В свою очередь, С.Н. Ильченко (2012) не отказываясь от классического деления жанров на три группы, предлагал выделить еще одну - группу жанров игрового телевидения.

При всем внешнем разнообразии основные работы, посвященные телевизионным жанрам, остаются, на наш взгляд, в одной методологической парадигме, сдоминирующим теоретическим осмыслением, предполагающим выделение множества жанровых категорий, и сильной зависимостью от филологической традиции. В этой ситуации актуальным становится вопрос о возможности и необходимости на современном этапе поиска иных подходов к формированию в академическом сообществе подходов к выделению и определению типов представления контента аудитории.

Начиная с середины 2010 гг. мы наблюдаем несколько важных, с нашей точки зрения, тенденций в изучении и теоретическом осмыслении журналистики и медиа в России, связанных в первую очередь с увеличением объемов эмпирической информации и расширением круга теоретических концепций, которые можно развивать за счет ее интеграции. В этом контексте можно вспомнить, например, работы, опирающиеся на сбор и анализ оригинальных эмпирических данных при развитии нормативных (Лазутина (ред.), 2018) и политэкономических (Макеенко, Кугушева, 2019) теорий функционирования медиа. В этом же направлении начинает развиваться и изучение форм подачи новостного контента. Так, работы А.В. Колесниченко (2018, 2019) о востребованности жанров в новостных онлайн-медиа, с одной стороны, сохраняют привычный подход к классификации, предполагающий выделение мно- жества жанров, но с другой - опираются на сбор и анализ значительных объемов эмпирической информации, которая позволяет проверять адекватность жанровой типологии и определять направления ее совершенствования. При этом, несмотря на частое использование термина «жанр» в своих работах, исследователь предлагает считать более точным, отвечающим научным и, главное, образовательным потребностям современного академического сообщества понятия «типы журналистских текстов» и «типы журналистского письма» (Колесниченко, 2017: 29-31).

Еще одна важная тенденция в российских исследованиях медиа последних лет возвращение интереса к изучению реальных редакционных практик журналисткой и редакторской работы, в рамках которых, в частности, затрагиваются вопросы о соотношении отдельных элементов теории журналистики и редакционных реалий. И проблема применимости жанровой теории к пониманию практических журналистских рутин уже попала в сферу актуальных исследовательских интересов (Вырковский, Галкина, Колесниченко, Образцова и др., 2017). При изучении особенностей работы журналистов и редакторов на современных новостных радиостанциях А.Ю. Образцова (2019) в ходе интервью с редакторами выявила реально используемую в редакциях терминологию, связанную с типами журналистских материалов, и после этого продолжила изучение журналистских практик с ориентацией именно на реальные редакционные подходы. Полученные результаты позволили сделать заключение о «перспективности использования эмпирических данных для модернизации отдельных разделов теории журналистики. В частности, изучение профессиональной терминологии, используемой журналистами и редакторами для обозначения производимых материалов, не только показывает разрыв между теорией и практикой, 
но и может быть основанием для модернизации жанровой теории для радио» (Образцова, 2019: 13).

На наш взгляд, эта концепция применима и к теории телевизионных жанров. В настоящее время уже предприняты попытки ревизии жанровой структуры новостных материалов на радио и онлайн, в то время как положение дел в телевизионных редакциях остается неизученным. Именно поэтому мы провели исследование форм подачи новостных материалов в редакциях крупнейших российских телеканалов, в ходе которого попытались ответить на вопросы об актуальности и адекватности сформированной академическим сообществом классификации телевизионных жанров.

\section{Методика}

На первом этапе изучения подходов к определению форм подачи контента на телевидении мы обратились к информационному сегменту, так как развлекательный, на наш взгляд, требует отдельного анализа, возможно с применением так называемого «форматного», или индустриального, подхода, который более популярен у западных исследователей.

Мы провели десять экспертных интервью с сотрудниками редакций информационного вещания российских телеканалов первого и второго мультиплекса, а также двух региональных московских телеканалов. Из первого мультиплекса были выбраны «Первый канал», «Россия 1», НТВ, «Пятый канал», ОТР, «ТВ Центр», из второго - каналы РЕН ТВ и «Звезда», из столичных телекомпаний в выборку попали представители редакций телеканалов «Москва-24» и «360». При выборе респондентов (далее P1, P2 и т.д.) приоритет отдавался практикам, работающим в новостных редакциях и непосредственно участвующим в создании информационных программ, - корреспондентам, редакторам, продюсерам (пятеро, двое и трое респондентов соответственно).

Интервью были разделены на несколько коротких этапов. Первый из них связан с выявлением возможностей применения в редакциях понятия «жанр», традиционно используемого для обозначения различных форм подачи контента в теории журналистики. Необходимо было получить ответы на следующие вопросы: Употребляете ли Вы в работе слово «жанр»? Если да, то в каких случаях? Если нет, то используется ли в Вашей редакции какое-то другое (единое) для всех способов представления информации слово? На втором этапе респондентам предлагалось проанализировать традиционную классификацию телевизионных жанров, предложенную В.Л. Цвиком, по ряду критериев: насколько жанры, которые входят в данную типологию, соответствуют современным формам представления информации на телевидении; есть ли среди них те, которые до сих пор используются в работе телевизионных журналистов; есть ли те, к которым работники редакций более не обращаются. Наконец, в завершении респондентам было предложено перечислить термины, которыми они пользуются на практике, а также коротко пояснить, что конкретно представляют собой материалы, обозначаемые указанными понятиями.

\section{Результаты исследования}

Первой задачей, которую мы ставили перед собой, было узнать у респондентов, пользуются ли они в работе понятием «жанр», а если нет, указать, каким термином оперируют для определения форм подачи информации. Лишь один из опрошенных признал, что употребляет это слово при общении с редакторами или корреспондентами его редакции. Остальные ответили отрицательно, указав, что слово «жанр» не звучит в редакциях уже много лет: 
«Нет. Слово "жанр" кто-то может вспомнить раз в миллион лет (P2);

Нет. Формат (РЗ);

Слово "жанр", если и употребляется, то скорее в ироничном контексте. В основном используются жаргонные словечки, которые, правда, могут отличаться в различных редакциях, регионах, городах. В качестве синонима, скорее, используется слово "формат", но крайне редко (Р4);

Нет, в работе ни я, ни мои коллеги слово "жанр" не употребляем. Другого обозначения нет (P5);

Не употребляем. Как мне видится, нет практической необходимости. Потому и замена этому слову не приходит в голову (Р6);

Нет, хотя обозначения жанров я иногда слышу, получая задание. Кпримеру, редактор говорит мне: "Запиши Лт" или твой сюжет ("ВМЗ") превратился в “Б3". Так или иначе, обычно выделяются такие понятия, как "сюжет" (ВМЗ), “прямое включение", “ЛТТ", "Б3" (Р7);

Нет, используем слово "материал" (Р8);

В работе крайне редко можно услышать слово "жанр" (Р9);

Материал в виде чего-то... ЛТТ, "прямо" и т.д. Слово "жанр" скорее заменили более модными: "эту историю надо снять, как..." (Р10)».

Два человека ответили, что в работе используется термин «материал", двое указали на понятие «формат». Остальные же отметили, что единого слова для обозначения различных форм презентации информации нет, работники редакций пользуются конкретными, понятными сотрудникам редакции названиями отдельных форм/форматов.

Далее мы предложили респондентам ознакомиться с классификацией телевизионных жанров В.Л. Цвика, активно использующейся в отечественном академическом дискурсе, проанализировать ее и указать, какие из форм сейчас используются на телевидении, а какие нет. Напомним, что автор классификации выделял три группы телевизионных жанров: жанры информационной публицистики (заметка) видеосюжет, отчет, выступление, интервью, репортаж), жанры аналитической публицистики (комментарий, обозрение, беседа, дискуссия, ток-шоу, пресс-конференция, корреспонденция/передача) и жанры художественной публицистики (очерк, зарисовка, эссе).

Стоит отметить, что в большинстве случаев респонденты испытывали трудности с ответами, поясняя, что данная классификация имеет мало общего с реальной практикой:

«Давно не штудировал учебники и слежу за деятельностью далеко не всех своих коллег, но для меня тут какая-то мешанина. Заметка - для меня - краткая новость в текстовом формате, а уж никак не видеосюжет. $<. .>$ Обозрение - туманное слово из какихто старых газет. Я его никогда не использовал даже в начале нулевых, когда работал в газетах. <...> Корреспонденция - это что-то про письма? Но тут же слово "передача" т.е., то, что сейчас принято называть "программа". Хотя программа - в моем понимании - очень размытое понятие само по себе, форматы и "жанры" в ее основе могут быть самые разные. Тут я совсем запутался (Р2);

Это речь про телевидение или...? (РЗ);

Мне кажется, что это устаревшая история: все эти жанры в принципе мало общего имеют с телевизионной журналистикой. Есть ощущение, что все жанры были взяты из печатной журналистики и некто попытался их адаптировать. Конечно, они частично имеют отношение к практике, но в основном они не имеют ничего общего с современной мировой тележурналистикой (Р7);

Исторические названия жанров сейчас скорее используются в ироничном контексте. Ну, никто не дает задание - "а сделай-ка, товарищ корреспондент, нам фельетон" (Р4)».

Впрочем, несмотря на затруднения, опрошенные смогли проанализировать большую часть жанров. Заметку/видеосюжет, как используемое понятие, отме- 
тили девять из десяти респондентов, однако некоторые уточнили: «Под заметкой подразумеваю просто "сюжет"» (P1).

«Отчет» выделили трое из десяти, «выступление» - четверо, «интервью» и «репортаж» - все десять респондентов. В группе жанров аналитической публицистики "комментарий» указали восемь из десяти опрошенных; «обозрение» шесть из десяти, при этом в отдельных случаях «под "обозрением» подразумевают «обзор». «Беседу» отметили трое респондентов, "дискуссию» - четверо, «ток-шоу» - абсолютное большинство. Трое указали, что «прессконференция" - это событие, а не жанр. «Корреспонденцию» отметил один человек.

В группе жанров художественной публицистики «очерк" указали четверо, при этом пояснили: «[Очерк] возможен, но на тематических каналах, а-ля "Культура" (РЗ)».

«Зарисовку» отметили также четверо респондентов, при этом прокомментировав: “[Зарисовку] можно назвать репортажем в ограниченном пространстве, повествующем о событии или месте на протяжении непродолжительного периода времени. Она как бы менее информационная, чем репортаж: например, [может рассказывать] о жизни монахов-отшельников (Р7)».

«Эссе» выделили трое респондентов, «фельетон» и «памфлет» - один, при этом пояснив: «Они не то, чтобы устарели. Просто перешли в разряд информационных продуктов на телеканалах с определенной политической и юмористической составляющей (Р10)».

Один из респондентов отметил, что все эти жанры умерли, но «есть надежда на возрождение этих жанров в связи с существующим запросом со стороны оставшейся интеллигентной аудитории. Тем более современные технические средства позволяют развернуться в полную творческую силу (Р4)». Отметим, что при анализе группы жанров художественной публицистики двое респондентов затруднились дать комментарий.
В целом же можно отметить интересную тенденцию. Почти все респонденты при анализе традиционной жанровой классификации приходили к выводу, что в отдельных журналистских материалах на телевидении можно обнаружить какие-то элементы тех или иных представленных в ней жанров. Однако как только на следующем этапе речь зашла не об отвлеченном теоретизировании, а о реальных редакционных практиках, в которые вовлечены корреспонденты и редакторы, из ответов складывалась совершенно иная картина.

Как мы и просили, каждый из опрошенных представил свой личный классификатор используемых «форм» презентации информации с краткими пояснениями указанием их технических и концептуальных характеристик. Мы сопоставили полученные ответы для того, чтобы выявить наиболее часто встречающиеся варианты (см. табл. 1 и 2).

Все формы представления информации мы разделили на две категории: в первую вошли те, в которых корреспондент принимает лишь косвенное участие, во вторую - авторские материалы (содержащие указание авторства).

В таблицы вошли все формы представления информации, предложенные двумя и более респондентами. Среди материалов, подготовленных при косвенном участии автора-корреспондента, самой популярной оказалась «БЗ» (Без Закадра, Без Звука; эту форму указали все десять респондентов). По четыре голоса набрали «срочно» («срочняк»)/«устно» («устняк») и «подводка». Трое опрошенных указали шпигель, двое - «трансляцию» и «дайджест».

В рамках интервью респонденты поясняли, что представляет собой каждая из указанных форм подачи информации. Далее дается одно из авторских определений респондентов и обобщение их формулировок. 
Таблица 1. Формы представления информации в телевизионной журналистике: материалы, подготовленные при косвенном участии автора-корреспондента

\begin{tabular}{|c|c|c|c|c|c|c|}
\hline $\begin{array}{l}\text { Фвтор- } \\
\text { корреспондент }\end{array}$ & 63 & $\begin{array}{c}\text { Устно } \\
\text { ("Устняк») / } \\
\text { Срочно } \\
\text { («Срочняк») }\end{array}$ & Подводка & Шпигель & Трансляция & Дайджест \\
\hline Респондент 1 & + & & + & & & \\
\hline Респондент 2 & + & & & & & \\
\hline Респондент 3 & + & + & + & & + & \\
\hline Респондент 4 & + & & & + & & + \\
\hline Респондент 5 & + & + & & & & \\
\hline Респондент 6 & + & + & + & & & \\
\hline Респондент 7 & + & + & & + & & + \\
\hline Респондент 8 & + & & & + & + & \\
\hline Респондент 9 & + & & & & & \\
\hline Респондент 10 & + & & + & & & \\
\hline
\end{tabular}

Таблица 2. Формы представления информации в телевизионной журналистике: материалы, подготовленные при активном участии автора-корреспондента

\begin{tabular}{|l|c|c|c|c|c|c|}
\hline $\begin{array}{l}\text { Автор- } \\
\text { корреспондент }\end{array}$ & $\begin{array}{c}\text { Сюжет } \\
\text { (ВМ3) }\end{array}$ & $\begin{array}{c}\text { Прямое } \\
\text { включение }\end{array}$ & Лтт & Репортаж & Интервью & Стрим \\
\hline Респондент 1 & + & + & + & & & \\
\hline Респондент 2 & + & + & + & & & + \\
\hline Респондент 3 & + & + & + & & & \\
\hline Респондент 4 & + & + & + & & & \\
\hline Респондент 5 & + & + & + & & & \\
\hline Респондент 6 & + & + & + & + & + & \\
\hline Респондент 7 & + & + & + & + & + & \\
\hline Респондент 8 & + & + & + & & & + \\
\hline Респондент 9 & + & + & & + & & \\
\hline Респондент 10 & + & + & & + & + & \\
\hline
\end{tabular}


Мини-инфо, которое читает в студии ведущий с одним синхроном или двумя (комментарий спикера или героя). (Р9): «БЗ», или «Без Звука» - очень распространенный термин в новостной телевизионной журналистике. «Бэзой» практики называют короткое (относительно сюжета, репортажа и пр.) информационное сообщение, которое зачитывается в прямом эфире ведущим. Текст может быть разбит на части синхронами, лайфами и пр. В этом случае могут появляться различные терминологические вариации: Б3-СНХ / Б3-СX («СНХ» и «СХ»- условные обозначения синхронов).

Ведущий в прямом эфире озвучивает текст; может быть перекрыто картинкой. (P7): «устно» («устняк») / «срочно» («срочняк») - наиболее короткая форма представления информации: по сути, это БЗ с меньшим хронометражем, без дополнительных элементов: синхронов, лайфов и пр. Название произошло от длинного «устное сообщение», которое подразумевало, что текст не появляется на суфлере и ведущий должен прочитать сообщение "устно», предварительно услышав его от шеф-редактора с помощью беспроводного микрофона. Впоследствии в обиход вошел также термин "срочно», который является вариацией «устно».

Съемка в прямом эфире определенного события; может быть и с комментарием ведущего, и без. (Р7): «трансляция» - форма представления информации, все более активно используемая в последнее десятилетие в силутехнической модернизации телевизионного продакшна. Как правило, представляет собой трансляцию какого-либо события в прямом эфире, может сопровождаться как комментариями ведущего или эксперта, так и передаваться без сопровождения (в этом случае будет напоминать рубрику No Comments на Euronews, однако есть различие в способе подготовки материала: трансляция всегда идет в прямом эфире, No Comments - в записи).
В подводке ведущий сообщает зрителю информационный повод - объявляет следующий сюжет. (P7): «подводка» - термин используется для обозначения выступления ведущего перед авторским материалом (сюжетом, репортажем, Лтт), применяется и в рамках прямого включения. Представляет собой короткий по хронометражу текст, в котором обозначается новость, о которой будет рассказано далее; иногда длительность увеличивается (например, в итоговых новостных программах за неделю «подводка» ведущего может длиться несколько минут).

Анонс в начале выпуска. (Р4): «шпигель» - термин, который используется для обозначения "сборки» анонсов различных материалов, включенных в новостную программу. Как правило, запускается в начале выпуска после приветствия ведущего, а также перед рекламными паузами. Может озвучиваться как в студии (ведущим) в прямом эфире, так и быть записан и смонтирован заранее (подр. см.: Чобанян, 2015: 80-99).

Нарезка кратких сообщений под музыку и/или звук секундомера. (Р4): «дайджест»понятие, использующееся для обозначения материала, который представляет собой нарезку из коротких сообщений (как правило, до 40 сек. каждое). Может начитываться как в студии ведущим (при этом сопровождаться или не сопровождаться дополнительным видеорядом), так и быть заранее подготовленным материалом (готовится корреспондентом или райтером без указания авторства, монтируется заранее). Часто в такого рода материалах применятся дополнительные средства оформления - например, звукового - на текст и видео «накладывается» музыка.

Среди материалов, подготовленных при активном участии автора-корреспондента, все респонденты выделили «сюжет» «ВМЗ» и «прямое включение». Восемь респондентов указали «ЛТТ», «репортаж» выделили 
четверо опрошенных, трое - «интервью», «стрим»-двое.

«Сюжет» - самая распространенная форма новостного сюжета. Чаще всего имеется в виду закадровый текст, разбавленный синхронами (фрагментами интервью), лайфами (яркими деталями, выраженными и звуком, и картинкой) и стендапами (когда корреспондент говорит в кадре, а не за кадром). (Р7): «сюжет» или «ВМЗ» («ВидеоМатериал со Звуком») - термин, имеющий очень широкое значение; “сюжетом» на телевидении могут быть названы все материалы, имеющие в своей основе закадровый текст и дополнительные структурные элементы - синхроны, лайфы, цитаты, стэндапы и пр.

Выступление корреспондента в прямом эфире, может прерываться синхронами, реже лайфами, иногда идет в связке с сюжетом. (Р7): «прямое включение» или «прямо» - эта форма презентации новостей представляет собой обращение корреспондента в прямом эфире в зрителям с рассказом о происшествии/ событии, которое происходит в реальном времени. Выстроена в виде телемоста с применением полиэкрана (ведущий и корреспондент), структуру образуют вопросы ведущего и ответы репортера, текст автора может быть также разбит на дополнительные структурные элементы: синхроны, лайфы и пр.

Нечто близкое к сюжету, но собранное очень быстро; визуально близко к прямому включению. (P2): может быть вообще без лайфов и синхронов - стендап-закадрстендап.

Ты записываешь на месте сюжет, но ты находишься в кадре, а потом часть этого «псевдопрямого» включения, так называемого, перекрывают уже непосредственно в редакции. (P1): «ЛПТ или «Лайфту-тэйп» - форма презентации новостей, по структуре повторяющая сюжет, однако вместо закадрового текста в материал ставятся стэндапы корреспондента. Могут встречаться различные вариации: как по съемке, так и по структуре (например, материал может представлять собой сборку стэндапов и закадрового текста без врезки синхронов, лайфов и пр.) (подр. см.: Никольская, 2019: 72-88).

Репортаж - это тот же сюжет, только с большей работой корреспондента, его нельзя сделать «из редакции» (P9).

Много работы на месте, сильная эмоциональная составляющая, множество деталей, характеризующих событие. (Р7): в большинстве редакций «репортаж» не выделяют отдельно, используя широкое понятие «сюжет». Однако если же в телекомпании понятие «репортаж» в ходу, то этим термином, как правило, называют материал с большим количеством стэндапов (при сокращении закадрового текста), с более частым появлением в кадре корреспондента - в том числе при съемке синхронов и лайфов, с увеличенным хронометражем, с использованием дополнительных способов получения информации (например, скрытая съемка), с обращением к реконструкциям и пр.

Записанное заранее или выведенное «в прямо» интервью с героем или экспертом. Может быть смонтировано с лайфами или синхронами о событии, которое является темой разговора. Порой есть даже художественные вставки, типа нарезок из фильмов или мультфильмов, если речь идет о развлекательной тематике. Отличается от синхрона тем, что ведущий или корреспондент находятся в кадре, вопросы звучат в эфире, а снято чаще всего с нескольких камер (Р7): термин «интервью» указали три респондента, пояснив, что понятие часто звучит в редакции, однако самостоятельной формой в программах новостей является редко, чаще представляет собой часть других материалов. Может быть отдельным в случае особо знакового информационного повода. 
Это та же трансляция, но в ней меньше внимания уделяется качеству материала. Может быть с элементами прямого включения корреспондента, а может быть растянуто на долгое время - в ожидании, что случится что-то в кадре. (Р7): «стрим» также является очень молодой и пока не очень растространенной на телевидении формой (чаще можно увидеть стримы на онлайнплатформах). Представляет собой, по сути, ту же трансляцию, отличие заключается в способе записи происходящего: если в случае странсляцией, съемка ведется с помощью профессиональной техники, заранее аккредитованной на мероприятие, то стрим получают с мобильных телефонов или лайф-ю и дежеро ( мобильных» рюкзаков). «Стрим» пришел на телевидение из социальных сетей и других онлайн-платформ (youtube.com, twitch.com, goodgame. com и пр.), и теперь используется, как правило, при происшествиях и других незапланированных событиях.

По одному разу были упомянуты такие формы материалов, как «БЗ-стэндап», «стена» и «анимация». Судя по всему, перечисленные формы являются вариациями привычных форм представления информации, придуманных в каждой конкретной редакции: “"Б3-стэндап" мы делаем, когда, например, идут военные учения в разных городах, в каждом у нас корреспонденты. Они записывают стэндапы, которые потом "склеиваются" через подводки ведущего (Р8); По структуре "стена" близка к сюжету, но вместо закадров (закадрового текста) корреспондент выходитв студию к ведущему, отвечает на обращенный к нему вопрос и рассказывает о событии на фоне экранов с инфографикой; рассказ все так же разбивается лайфами и синхронами (Р2); "Анимация" - это то же, что ВМЗ, но с графикой вместо смонтированного видеоряда (Р4)».

Можно заметить, что «БЗ-стэндап» напоминает обычную БЗ с тем исключением, что вместо синхронов, лайфов и пр. используются стэндапы, что нетипично для этой формы. «Стена» же весьма похожа по структуре на прямое включение, но не с места событий, а из студии. «Анимация», по сути, является «сюжетом» с графикой. Скорее всего, самостоятельный термин используется для удобства сотрудников конкретной редакции.

Некоторые формы материалов, к которым обращаются практики, отчасти схожи с теми, о которых пишут авторы работ по телевизионной журналистике. Так, «заметка» представляет собой «БЗ» (есть различие в самом рабочем термине). При этом может возникать вопрос: почему в теоретической типологии «заметка» синонимична «видеосюжету», тогда как на практике это кардинально разные вещи. «Репортаж» и «интервью» совпадают, хотя, например, современные трактовки интервью журналистами оказываются богаче, чем в теории.

\section{Заключение}

Результаты настоящего исследования показали, что терминологический аппарат, которым в реальной работе пользуются сотрудники российских телеканалов, минимально пересекается с концепциями жанровой теории телевизионной журналистики. Анализ наиболее авторитетной академической типологии жанров вызвал у корреспондентов, редакторов и продюсеров большие трудности, что может говорить о значительных различиях в подходах к определению типов контента. Информация, полученная от практикующих журналистов, также показала, что многие жанры, до сих пор глубоко интегрированные в академический дискурс, не актуальны на современном телевидении или же ограниченно представлены в редакционных практиках.

Важнейшие отличия в подходах заключаются в том, что терминология, используемая в рабочих практиках, в гораздо большей степени ориентирована не на смысловые/ содержательные, а на технические харак- 
теристики подготовки и подачи журналистских материалов. Возможно, это является одним из объяснений того, что журналисты и не пользуются фундаментальным для теории понятием «жанр». В этом контексте имеет смысл, вероятно, не столько радикально пересмотреть сформировавшуюся в академическом сообществе жанровую теорию, сколько ввести как более адекватное отражению реалий функционирования современной телевизионной журналистики понятие «формы подачи информации». В этом случае в исследовательской работе можно будет отталкиваться не только от изучения готовых телевизионных медиатекстов с применением формально далеких от реального контекста их создания и существования филологических критериев, но и ориентироваться на вовлечение в контекст актуальных редакционных рутин.

Главным же результатом актуализации подходов к формированию академического дискурса будут не столько изменения научного дискурса, сколько трансформации дискурса образовательного. В последнем до сих пор доминируют подходы к обучению телевизионной журналистике на основе жанровой теории, в то время как переориентация на освоение «форм подачи информации» может расширить области пересечения журналистского образования с реальным функционированием современной журналистики.

\section{Библиография}

Багиров Э., Борецкий Р., Груховская Л., Григорьянц Н. и др. Жанры телевидения. М.: [б. и.], 1967.

Борецкий Р.А. Информационные жанры телевидения. М.: [б. и.], 1961.

Виноградова У.Е. Методические проблемы развития классификации деловых медиа // Медиаскоп. 2019. Вып. 3. Режим доступа: http://www.mediascope.ru/2572 DOI: 10.30547/mediascope.3.2019.11

Вырковский А.В., Галкина М.Ю., Колесниченко А.В., Образцова А.Ю. и др. Трансформация журналистской работы под влиянием новых технологий: поиск информации, жанры медиатекстов, редакционная культура // Вестн. Моск. ун-та. Сер. 10: Журналистика. 2017. № 5. С. 51-71.

Журналистика в информационном поле современной России: должное и реальное / под ред. Г.В. Лазутиной. М.: Аспект Пресс, 2018.

Ильченко С.Н. Трансформация жанровой структуры современного отечественного телеконтента: актуализация игровой природы телевидения: дис. ... д-ра филол. наук. М., 2012.

Ким М.Н. Жанры современной журналистики. СПб.: Изд-во Михайлова В.А, 2004.

Колесниченко А.В. Востребованность жанров журналистских текстов в онлайновых СМИ // Вестн. Моск. ун-та. Сер. 10: Журналистика. 2018. № 1. С. 26-42.

Колесниченко А.В. Востребованность жанров журналистских текстов аудиторией онлайновых медиа // Вестн. Моск. ун-та. Сер. 10: Журналистика. 2019. № 3. С. 3-22. DOI: 10.30547/vestnik.journ.3.2019.322 
Колесниченко А.В. Техника и технология СМИ. Подготовка текстов. М.: Юрайт, 2017.

Кройчик Л.Е. Система журналистских жанров // Основы творческой деятельности журналиста / под ред. С.Г. Корконосенко. СПб.: Изд-во Михайлова В.А., 2000.

Кузнецов Г.В., Цвик В.Л., Юровский А.Я. Телевизионная журналистика. М.: Изд-во Моск. ун-та; Высш. шк., 2002.

Лазутина Г.В., Распопова С.С. Жанры журналистского творчества. М.: Аспект Пресс, 2012.

Майдурова О.Ф. Информационные жанры в региональных новостных телепрограммах: актуальные тенденции. СПб.: СПбГу, 2011.

Макеенко М.И., Кугушева А.А. Возможности использования политической экономии коммуникации в российской теории медиа // Медиаскоп. 2019. Вып. 4. Режим доступа: http://www.mediascope.ru/2574 DOI: 10.30547/mediascope.4.2019.1

Никольская Э.С. Место ЛтТ в жанровой палитре телевизионных новостей // Вестн. Моск. ун-та. Сер. 10: Журналистика. 2019. № 5. C. 72-88. DOI: 10.30547/vestnik. journ.5.2019.7288

Образцова А.Ю. Особенности работы корреспондентов и редакторов на современных новостных радиостанциях России: дис. ... канд. филол. наук. М., 2019.

От теории журналистики к теории медиа. Динамика медиаисследований в современной России: колл. моногр. / под ред. Е.Л. Вартановой. М.: Изд-во Моск. ун-та; Фак. журн. МГУ, 2019.

Пельт В.Д. Дифференциация жанров газетной публицистики: учеб.-метод. пособие для студентов фак. и отд. журналистики гос. ун-тов. М.: Изд-во Моск. ун-та, 1984.

Тертычный А.А. Жанры периодической печати. М.: Аспект Пресс, 2011.

Ученова В.В. Метод и жанр: Диалектика взаимодействия // Методы журналистского творчества. М.: Изд-во Моск. ун-та, 1982. С. 75-89.

Хлызова А.А. Обновление системы телевизионных жанров в современных медиаусловиях // Журналистский ежегодник. 2015. № 4. С. 73-76.

Чобанян К.В. Современный информационный телеканал: жанровые приоритеты и языковая модель. М.: Фак. журн. МГУ, 2018.

Чобанян К.В. Языковые средства и приемы привлечения внимания зрителей телевизионных новостей (на материале шапок и шпигелей телеканала Си-эн-эн) // Вестн. Моск. ун-та. Сер. 10: Журналистика. 2015. № 3. С. 80-99.

Шестеркина Л.П., Николаева Т.Д. Методика телевизионной журналистики. М.: Аспект Пресс, 2012.

Crump S. (1974) Fundamentals of Journalism. New York: McGraw-Hill Companies. Hornby R. (1965) The Press in Modern Society. London. 